\title{
An unusual sequence arrangement in the telomeres of the germ-line micronucleus in Tetrahymena thermophila
}

\author{
Karen E. Kirk and Elizabeth H. Blackburn ${ }^{1}$ \\ Department of Microbiology and Immunology, University of California at San Francisco, \\ San Francisco, California 94122 USA
}

\begin{abstract}
The ciliated protozoan Tetrahymena thermophila contains two nuclei that differ dramatically in function, chromosome size and number, chromatin structure, and mode of division. It is possible that the telomeres of the two nuclei have different functions. Although macronuclear telomeric DNA has been well characterized and consists of tandem $G_{4} T_{2} / C_{4} A_{2}$ repeats that are synthesized by the enzyme telomerase, micronuclear telomeres have not been isolated previously. Here, we report the identification and cloning of micronuclear telomeres and demonstrate that although they contain the same terminal tandem $G_{4} T_{2}$ repeats as macronuclear telomeres, they are strikingly different in three respects. First, the tracts of G/C-rich telomeric repeats are approximately seven times longer in the micronucleus than in the macronucleus $(\sim 2.0-3.4 \mathrm{vs}$. $\sim 0.3-0.5 \mathrm{~kb}$, respectively) from the same cell population. Second, the immediate telomere-associated sequences (TASs) from six different micronuclear chromosome ends have an unusually high G/C content and degree of homology to one another, unlike macronuclear TASs. The TAS from at least one micronuclear chromosome is unique to micronuclear telomeres and is not present in the macronucleus. Finally, and unexpectedly, all micronuclear telomere clones contain an inner homogeneous tract of a variant $G_{4} T_{3}$ repeat adjacent to the distal tract of $G_{4} T_{2}$ repeats. The native micronuclear telomeric DNA is composed of approximately $30 \% \mathrm{G}_{4} \mathrm{~T}_{3}$ repeats, corresponding to $0.6-1.0 \mathrm{~kb}$ per average telomere, positioned centromere-proximally to most or all of the $G_{4} T_{2}$ repeats. Neither the $G_{4} T_{3}$ sequence nor any other variant repeat is found in macronuclear telomeres. Furthermore, such a homogeneous tract of a variant repeat has not been found in the telomeres of any eukaryote.
\end{abstract}

[Key Words: Tetrahymena thermophila; micronuclear telomere; telomeric repeats; telomere-associated sequences]

Received September 23, 1994; revised version accepted November 10, 1994.

The regions near eukaryotic chromosome ends appear to have many functions, most of which are poorly understood. It has been well established that the distinctive simple G/C-rich DNA repeats usually found at telomeres are synthesized by the enzyme telomerase (for review, see Greider 1991; Blackburn 1992, 1994|, providing a means for the complete replication of the chromosome. In addition, telomeres provide a protective "cap" that prevents the natural ends from fusing, thus differentiating them from broken ends, an observation that has been long recognized (McClintock 1939, 1941; Muller and Herskowitz 1954). A broken end created by the loss of a telomere causes cell cycle arrest in yeast and, by what may be a separate mechanism, greatly increases chromosome loss (Bennett et al. 1993; Sandell and Zakian 1993). In another very different role, telomeres have the capacity to repress the expression of nearby genes (Gottschling et al. 1990). Telomeric repeats can influence silencing

${ }^{1}$ Corresponding author. when positioned chromosome internally (Stavenhagen and Zakian 1994) and, when present on a yeast circular plasmid, can greatly increase the mitotic stability of the plasmid (Longtine et al. 1992, 1993).

Telomeres have been observed cytologically to occupy defined positions within the nucleus during interphase, mitosis, and meiosis, but the particular localization can vary between organisms and cell types. The significance of these spatial orientations is not understood. In Schizosaccharomyces pombe (Funabiki et al. 1993), Trypanosoma brucei (Chung et al. 1990), and Drosophila melanogaster (Hochstrasser et al. 1986), telomeres localize to the periphery of interphase nuclei and frequently associate with each other. In Saccharomyces cerevisiae, the telomere-binding protein Raplp and, by inference, the telomeres, is also found in clusters at the nuclear periphery (Klein et al. 1992; Palladino et al. 1993). During meiotic prophase in many organisms, the chromosome extremities have been observed to associate with one another and to localize to the nuclear envelope (Dan- 
cis and Holmquist 1979). In maize zygotene, telomeres are found at the nuclear periphery and adjacent to the nucleolus (Dawe et al. 1994; H. Bass, Z. Cande, and J. Sedat, pers. comm.). Recent observations in living $S$. pombe have suggested that telomeres may have a prominent role in a very dramatic nuclear movement during karyogamy and meiosis: The telomeres are found in a single cluster colocalized with the spindle pole body at the leading edge of the elongated moving nucleus (Chikashige et al. 1994). Thus, the list of potential telomere functions continues to expand.

Tetrahymena thermophila provides a unique system for potentially dissecting the multiple roles of telomeres. Like most ciliates, T. thermophila possesses two nuclei within a single cell, which differ dramatically in terms of function, chromosome content and chromatin structure, and mode of division (for review, see Blackburn and Karrer 1986; Prescott 1994). Therefore, It is possible that the telomeres in the two nuclei have very different functions, possibly reflected in different structures and mode of synthesis. The macronucleus contains hundreds of different subchromosomal pieces, each having a copy number of $\sim 50$, except for the rDNA chromosome, which is amplified to $\sim 10^{4}$ copies (for review, see Kapler 1993). The macronuclear chromosomes are acentric, and the macronucleus divides amitotically without chromosome condensation; the resulting daughter cells can differ significantly in their DNA content. The macronucleus is the sole source of gene expression during vegetative growth. The micronucleus, on the other hand, would appear similar to most eukaryotic nuclei, as it contains only five pairs of metacentric chromosomes, divides mitotically, and can undergo meiosis. Nevertheless, its functional repertoire is limited, as its main role is providing the germ line of the cell rather than gene expression. Upon conjugation, the diploid micronuclei in both partners undergo meiosis and cross-fertilization to form new micronuclei. In each cell, the old macronucleus is then destroyed, and a new macronucleus is differentiated from a copy of the new micronucleus. The micronucleus is transcriptionally silent throughout the life cycle except for a brief period early in meiotic prophase, and it is not known which RNAs are synthesized at this time (Sugai and Hiwatashi 1974; Martindale et al. 1985). Throughout vegetative growth, the micronuclear chromatin structure reflects the transcriptionally inert state and contains certain histone and linker proteins that are markedly different from those in the macronucleus (e.g., Allis et al. 1984; Stargell et al. 1993; Stargell and Gorovsky 1994).

The $T$. thermophila macronuclear telomeres contain $\sim 300-500$ bp of the repeated sequence $G_{4} T_{2}$. The synthesis of macronuclear telomeres has been well studied, and is carried out by the ribonucleoprotein telomerase, which provides the templating telomeric repeat sequence within its RNA moiety (for review, see Blackburn 1990, 1992). By introducing a telomerase RNA gene bearing an altered template sequence into the macronucleus, the repeat sequence of the distal regions of macronuclear telomeres has been changed artificially from
$\mathrm{G}_{4} \mathrm{~T}_{2}$ to, for example, $\mathrm{G}_{4} \mathrm{TC}$ (Yu et al. 1990). In these transformants, the macronuclear telomeres are lengthened and acquire the variant repeat sequence. The phenotype of these cells is drastic: The macronuclei become grossly enlarged and ultimately cease to divide ( $\mathrm{Yu}$ et al. 1990). The presence of the specific repeat sequence $G_{4} T_{2}$ on the distal regions of the telomeres, therefore, is important for some poorly understood telomere function in the macronucleus, independent of telomerase recognition and elongation. It is not known what role, if any, wild-type telomeres play in chromosome segregation or in the amitotic division of the macronucleus, and the spatial organization of telomeres in the macronucleus is unknown.

Micronuclear telomeres have not been isolated previously, primarily because of their relative scarcity in the cell, and nothing is known about their synthesis or function. Because the micronucleus is not transcribed and the macronucleus carries a single copy of the telomerase RNA gene (Greider and Blackburn 1989; Romero and Blackburn 1991), it is likely (but has not been proven) that the telomeres of both nuclei are synthesized by the same telomerase components of macronuclear origin and, therefore, that the micronuclear telomeres are also composed of $\mathrm{G}_{4} \mathrm{~T}_{2}$ repeats. The micronuclear chromosomes contain numerous stretches of nontelomeric $\mathrm{G}_{4} \mathrm{~T}_{2}$ tracts, a factor that has also hindered the cloning of micronuclear telomeres (Yao and Yao 1981). The chromosomal position and function of these internal tracts is not known, but frequently they are associated with a class of transposon-like elements (Cherry and Blackburn 1985). Interestingly, all internal telomere-like DNA tracts are eliminated from the chromosomes during differentiation to the transcriptionally active macronucleus.

As a first step toward understanding the functions and synthesis of micronuclear telomeres during vegetative growth and meiosis, we report here the identification and cloning of the $T$. thermophila micronuclear telomeres. We show that although the distal repeat sequence is $G_{4} T_{2}$ as in macronuclear telomeres, the micronuclear telomeres are unique in several respects.

\section{Results}

\section{Identification of micronuclear telomeres}

Macronuclear telomeric repeats have been well characterized in $T$. thermophila and consist virtually exclusively of $\mathrm{G}_{4} \mathrm{~T}_{2}$ repeats (Budarf and Blackburn 1986; Spangler et al. 1988). Initial hybridization studies indicated that micronuclear telomeres contain the same repeat sequence (Shampay and Blackburn 1989). However, these telomeres have been very difficult to identify largely because of two reasons. First, the micronuclear genome contains $\leqslant 100$ stretches of nontelomeric $\mathrm{G}_{4} \mathrm{~T}_{2}$ tracts (Yao and Yao 1981). Thus, hybridization to the telomeres is obscured by the internal $G_{4} T_{2}$ repeats. Second, the micronucleus and macronucleus contain 20 and $\sim 4 \times$ $10^{4}$ chromosome ends, respectively. Hence, even greatly 
purified micronuclei still contain high levels of contaminating macronuclear telomeres; a previous attempt to clone micronuclear telomeres by functional analysis in yeast yielded only internal micronuclear $\mathrm{G}_{4} \mathrm{~T}_{2}$ tracts and macronucelar telomeres (Shampay and Blackburn 1989).

Initially, we attempted to identify micronuclear telomeres by assaying for $G_{4} T_{2}$ repetitive sequences that are preferentially sensitive to shortening by Bal31 exonuclease, a commonly used test for telomeric DNA (e.g., Cross et al. 1989; McEachern and Hicks 1993). Micronuclei were purified from the progeny of recently mated $T$. thermophila to minimize the loss or rearrangement of micronuclear DNA that may occur with extended passaging of vegetatively growing cells (Wyman and Blackburn 1991). DNA from the purified micronuclei was subjected to Bal31 treatment, and at various times during digestion, aliquots were removed and enzymatic activity was stopped. To monitor the rate of digestion, $\lambda$ HindIIIdigested DNA was included in the reaction. The samples were then digested with HindIII, and DNA fragments were separated by agarose gel electrophoresis under conditions that resolve high molecular weight products. A Southern blot of this gel was probed with a radiolabeled oligonucleotide consisting of the macronuclear telomeric sequence $\left(\mathrm{C}_{4} \mathrm{~A}_{2}\right)_{4}$ (Fig. 1A). This analysis revealed two hybridizing bands, indicated by arrows in Figure 1A, whose migration changed over time relative to the stationary bands from hybridization to internal telomerelike repeats. The upper of these two candidate telomeric fragments is seen as the appearance of a band at the 4-min time point, and the lower candidate is seen as the shortening of a diffuse band from the 0 - to 2-min time points. On the basis of the change in migration, $\sim 1 \mathrm{~kb}$ was digested from each of these fragments, consistent with the rate of Bal31 digestion of $\sim 250 \mathrm{bp} / \mathrm{min}$ determined from the $\lambda$ HindIII-digested DNA /data not shown). These results suggested that the micronuclear telomeric $\mathrm{G}_{4} \mathrm{~T}_{2}$ tracts are longer than $1 \mathrm{~kb}$, which is considerably longer than macronuclear telomeres.

Previous evidence indicated that internal micronuclear $\mathrm{G}_{4} \mathrm{~T}_{2}$ tracts are generally less than several hundred base pairs (Cherry and Blackburn 1985), and therefore, we reasoned that the background from internal tracts could be eliminated by digesting the micronuclear DNA with a frequently cutting restriction enzyme, and subsequently separating the smaller internal tracts from the larger telomeric fragments. The enzyme MseI (recognition sequence AATT) was selected because it cuts the extremely A/T-rich $T$. thermophila DNA roughly every 100 bp. After a Bal31 digestion time course, micronuclear DNA was cleaved with $M s e I$. These samples were then analyzed by Southern blotting using the same $\left(\mathrm{C}_{4} \mathrm{~A}_{2}\right)_{4}$ telomeric oligonucleotide as above (Fig. 1B). The results clearly revealed the true telomeres, visible as a broad smear that becomes shorter during Bal31 digestion. The bulk of the initial telomeric hybridization signal is between 2.0 and $3.4 \mathrm{~kb}$. It is likely to consist almost entirely of telomeric repeats (shown below), as MseI cleaves $\sim 100 \mathrm{bp}$ from the start of the repetitive DNA. In a similar assay, purified macronuclear DNA

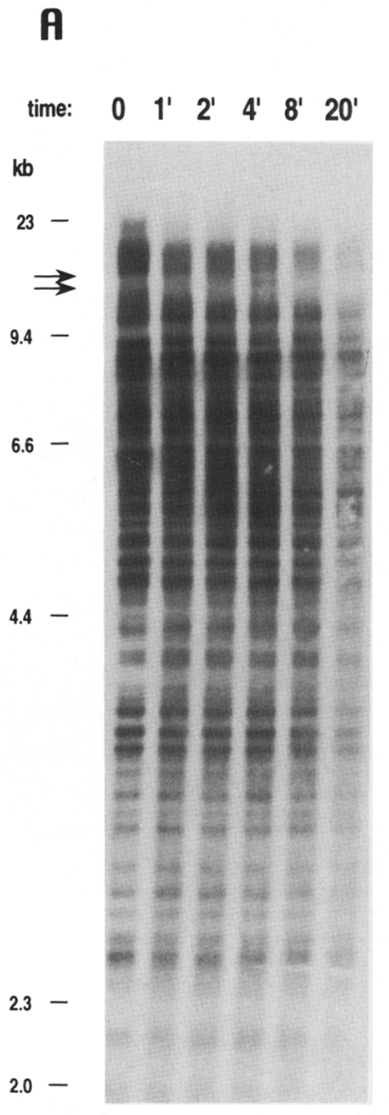

\section{B}

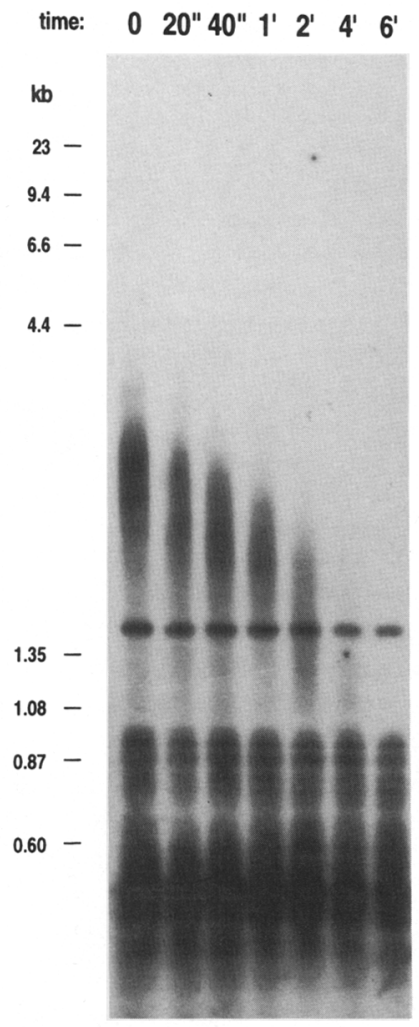

Figure 1. Southern blot analysis of Bal31-digested micronuclear DNA. Purified micronuclear DNA was digested with Bal31 exonuclease, and aliquots were removed and enzymatic activity stopped at the indicated times. The DNA was then digested with $H$ indIII $|A|$ or the frequently cutting enzyme MseI (B). DNA fragments were separated by agarose gel electrophoresis, and Southern blots were probed using an oligonucleotide with the telomeric repeat sequence $\left(\mathrm{C}_{4} \mathrm{~A}_{2}\right)_{4}$. Two Bal31-sensitive fragments are barely detectable in $A$, indicated by arrows. The endonucleolytic activity of Bal 31 causes a general loss of DNA with extended digestion, apparent at the last time point.

from the same cell population was run alongside micronuclear DNA, and the telomeric signal /which was nearly 100 times stronger) was centered $\sim 500 \mathrm{bp}$, with no hybridization signal observed above $1.4 \mathrm{~kb}$ /data not shown). Hence, the smear observed in Figure 1B was not attributable to contaminating macronuclear DNA.

\section{Cloning micronuclear telomeres}

To clone micronuclear telomeres, we developed a strategy to eliminate contamination from the internal $G_{4} T_{2}$ sequences and from macronuclear telomeres. Micronuclear DNA was digested with Bal31 such that $\sim 500 \mathrm{bp}$ was lost from the ends, thereby completely digesting away most contaminating macronuclear telomeres but leaving $>75 \%$ of the micronuclear telomeric tracts. NotI linkers were then added to this DNA to place a rare 
restriction enzyme site immediately adjacent to the telomeric $\mathrm{G}_{4} \mathrm{~T}_{2}$ tracts, thus differentiating the telomeres from the internal $G_{4} T_{2}$ tracts. The DNA was digested with NotI and Tsp509I, which cuts $T$. thermophila DNA very frequently and leaves termini complementary to those produced by EcoRI digestion. After separation on an agarose gel, DNA in the region corresponding to 1.0$3.5 \mathrm{~kb}$ was purified and cloned into a NotI-EcoRI-digested $\lambda$ ZapII vector, and plaques were screened by hybridization to a $\left(\mathrm{C}_{4} \mathrm{~A}_{2}\right)_{4}$ telomeric oligonucleotide.

From this screen, 20 positively hybridizing plaques were identified and the inserts were sequenced. Of these, 19 clones contained NotI sites immediately adjacent to a tract of telomeric repeats with the linker present in the orientation indicative of ligation to a telomere. The clones varied in the number of telomeric repeats they contained (the repeats are discussed below), but all were probably the result of deletions during the cloning process in Escherichia coli, as the insert sizes ranged from 300 to $850 \mathrm{bp}$. All clones contained $\sim 60-100 \mathrm{bp}$ of complex telomere-associated sequence (TAS) beginning with the predicted Tsp509I restriction site. The clones were categorized by TAS. Six independent chromosome ends could be identified by virtue of their differing TAS, labeled TAS A through TAS $F$ in Figure 2. Because the micronuclear genome contains 10 pairs of chromosome ends, we have identified more than half of the TASs, if each chromosome end has a unique sequence and not accounting for allelic variation in heterozygotes. For each TAS, from two to five independent clones were obtained. All of these TASs have a high degree of homology to each other, ranging from 55 to $87 \%$ identity. In addition, these sequences have an unusually high G/C content (ranging from 35 to $44 \%$ overall, and particularly high near to the telomeric repeats|, relative to the $\sim 25 \%$ overall G/C content of the T. thermophila genome (Prescott 1994). There are no other obvious sequence features, except for an imperfect inverted repeat, indicated by open arrows in Figure 2, present in five of the six sequences.

To verify the telomeric position and micronuclear origin of the cloned inserts, we investigated whether one of the cloned sequences (TAS A) was specific to micronuclear telomeres. To obtain a hybridization probe containing no telomeric repeats, a TAS fragment was made by
PCR using the primers indicated by solid arrows in Figure 2 with a TAS A-containing clone as template. This 89-bp PCR product was then used as a probe for Southern blot analysis of DNA from separately purified micronuclei and macronuclei which had been digested with Bal31 for various times, then cleaved by HindIII (Fig. 3). The fragment hybridizing to the TAS A probe was shortened and then lost during the Bal31 time course, indicating that this sequence does reside at a telomere. Under these relatively stringent conditions, this sequence was limited to the micronuclear telomere, that is, it was not present elsewhere in the micronuclear genome as a Bal31-resistant band. In addition, TAS A was not found in macronuclear DNA, indicating that this sequence is eliminated during macronuclear development. As a control for the telomeric specificity of Bal31 digestion and for the presence of macronuclear DNA on the blot, the blot was stripped and reprobed with a radiolabeled fragment from the $T$. thermophila telomerase RNA gene (Fig. 3). As anticipated, this sequence was present in the DNA from both nuclei and was resistant to Bal31.

\section{The centromere-proximal telomeric repeat sequence is $G_{4} T_{3}$ in all clones}

Upon sequencing through the TASs of the cloned micronuclear telomeres, we were surprised to find that in all 19 independent clones, the sequence immediately adjacent to the complex TAS was not $\mathrm{G}_{4} \mathrm{~T}_{2}$ as expected but, rather, $\mathrm{G}_{4} \mathrm{~T}_{3}$ (Fig. 4 ; four examples are presented). In every clone, the repetitive telomeric sequence began with at least one $G_{4} T_{3}$ repeat. In 17 of the 19 clones, large tracts of $\leqslant 45 \mathrm{G}_{4} \mathrm{~T}_{3}$ repeats were present. The number of $\mathrm{G}_{4} \mathrm{~T}_{3}$ repeats within each tract varied between clones, and the average was 28 repeats. These tracts were immediately adjacent to the more distal stretches of the expected telomeric repeat sequence $\mathrm{G}_{4} \mathrm{~T}_{2}$, and the junction between the two domains (indicated by arrowheads in Fig. 4) was $G_{4} T_{3} G_{4} T_{2}$ in all 19 clones except one. In no cloned telomere did we find any interspersion of the two types of repeat; out of $>10^{3}$ repeats sequenced, all were confined to their distinct $G_{4} T_{3}$ or $G_{4} T_{2}$ repeat domain.

More surprising than the existence of a variant repeat in the micronuclear telomeric DNA was the homogeneity of the $G_{4} T_{3}$ repeats, clearly seen from the sequencing
Figure 2. Sequence of six TASs, identified from 19 different clones. Homology alignments were performed using TAS C for comparison, facilitated by the Altschul DNA sequence alignment program. Dashes represent identity, and dots represent gaps. All clones had the Tsp509I restriction site (AATT) at the 5 ' end. Solid arrows represent the position of primers used to synthesize a PCR product of TAS A. Open arrows represent the imperfect inverted repeat found in five TASs. The start of the telomeric repeats is shaded.

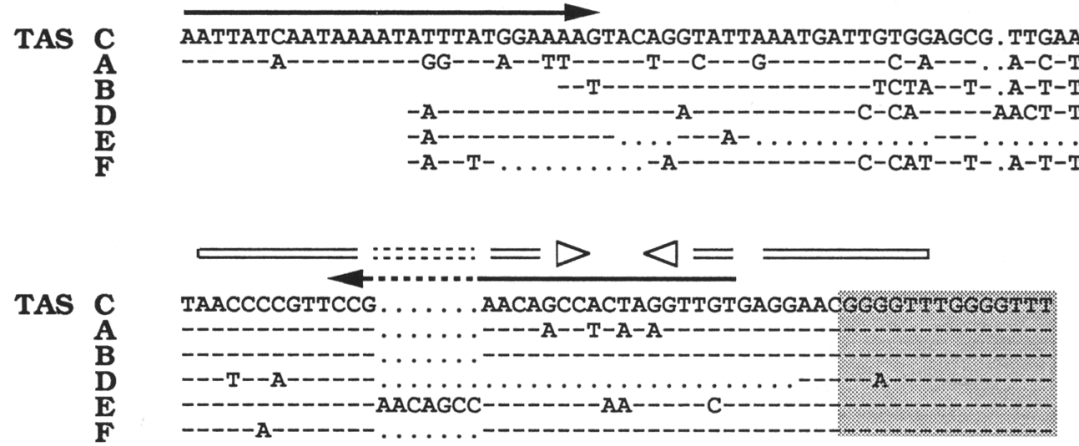




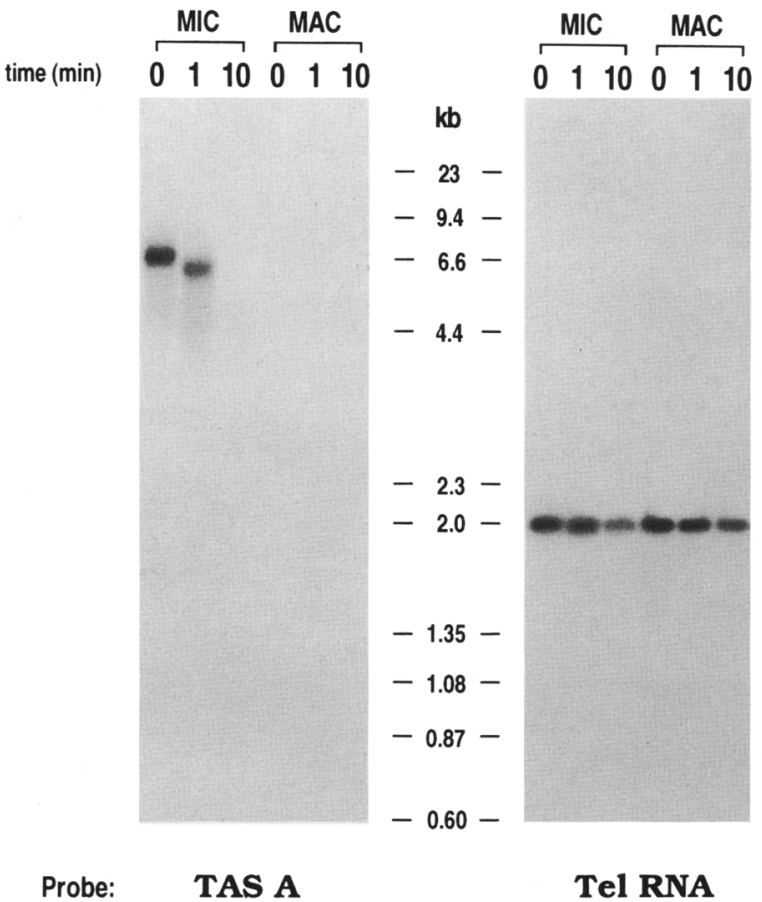

Figure 3. Southern blot analysis of Bal31-digested purified micronuclear (MIC) and macronuclear (MAC) DNA. DNA was digested with Bal31 exonuclease, and aliquots were removed and enzymatic activity stopped at the indicated times. The DNA was then digested with HindIII, and fragments were separated by agarose gel electrophoresis. A Southern blot was probed with a radiolabeled PCR product of TAS A, where indicated. This probe was then removed from the blot, and the blot was reprobed with a radiolabeled fragment of the macronuclear telomerase RNA gene, where indicated, as a control. Some overall loss of DNA occurred at the last time point, because of the endonucleolytic activity of Bal31.

data of the four clones in Figure 4. Accurate sequencing data were obtained from $\geqslant 200$ repeats in the cloned $\mathrm{G}_{4} \mathrm{~T}_{3}$ domains, and none contained any sequence other than $G_{4} T_{3}$. In addition, we searched for pattern changes among the longer sequencing products from copying the C-rich strand and found no indication of a single base change. Thus, it is highly likely that none of the total of 476 repeats found in the cloned $G_{4} T_{3}$ domains contained any variation in sequence. Similarly, all information that we obtained from reading either telomeric DNA strand indicated that there were no sequence variations among the 529 repeats of the $G_{4} T_{2}$ domains.

\section{$G_{4} T_{3}$ repeat content and distribution in native micronuclear telomeres}

As mentioned above, it was evident from the insert sizes that all the telomere clones obtained had lost telomeric repeats by unknown processes during cloning. Therefore, to analyze the overall $\mathrm{G}_{4} \mathrm{~T}_{3}$ repeat content and distribution in native micronuclear telomeres, we used differential hybridization to $G_{4} T_{2}$ and $G_{4} T_{3}$ oligonucleotides to distinguish between the two different repeat sequences. Two plasmids were used as controls: one containing a 21-repeat $G_{4} T_{2}$ insert $\left(\mathrm{pG}_{4} \mathrm{~T}_{2}-21\right)$, and the other containing an 18-repeat $\mathrm{G}_{4} \mathrm{~T}_{3}$ insert $\left(\mathrm{pG}_{4} \mathrm{~T}_{3}-18\right)$. Thus, the total length of the telomeric DNA tract was $126 \mathrm{bp}$ in each plasmid. Optimal specificity was obtained with two oligonucleotides having the sequences $G_{2}\left(G_{4} T_{2}\right)_{3} G$ and $\mathrm{T}_{3}\left(\mathrm{G}_{4} \mathrm{~T}_{3}\right)_{3}$, designed to maximize mismatches to the nonspecific telomeric repeat, washed at a temperature of $55^{\circ} \mathrm{C}$ (see Materials and methods).

To quantitate the level of hybridization obtained with either probe and to determine the levels of cross-hybridization to the nonspecific sequences, two identical dot blots were prepared having duplicate spots of fivefold serial dilutions of $\mathrm{pG}_{4} \mathrm{~T}_{2}-21, \mathrm{pG}_{4} \mathrm{~T}_{3}-18$, and control Bluescript plasmid alone. First, as the control for the molar quantity of plasmid on the dot blot, hybridization to a radiolabeled oligonucleotide corresponding to the $\mathrm{T} 7$ promoter in the Bluescript plasmid was used (Fig. 5; only the 20-ng spot is shown in the bottom row). The T7 promoter probe was then removed, and the same blots were reprobed with either the $\mathrm{G}_{4} \mathrm{~T}_{2}$ - or $\mathrm{G}_{4} \mathrm{~T}_{3}$-specific oligonucleotide (Fig. 5, top three rows). For both oligo-

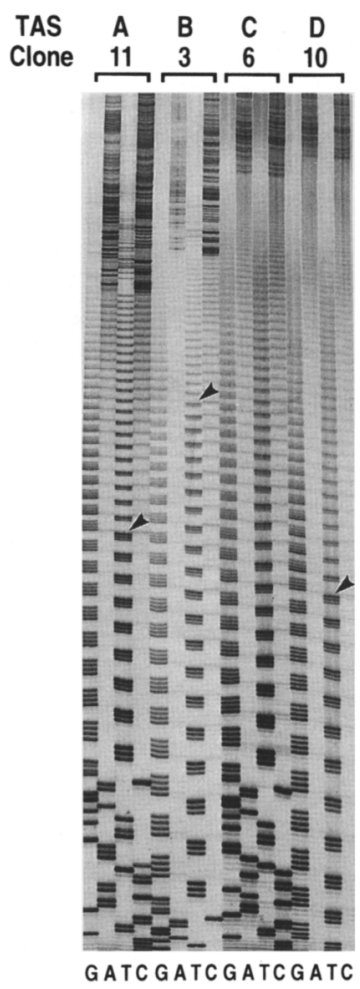

Figure 4. Sequence analysis of telomeric repeats from four different micronuclear telomere clones. The T7 promoter sequence was used as the sequencing primer to synthesize through the TAS of the G-rich strand. The transition from $G_{4} T_{3}$ to $G_{4} T_{2}$ repeats is indicated by arrowheads for clones 11,3 , and 10. In clone 6 , the transition was located more distally, and the results from the longer products were more difficult to read. In this case, the transition was determined from sequencing reactions of the opposite strand (not shown). 
Figure 5. Dot blot hybridization analysis to determine hybridization signal intensity and crossreactivity of $G_{4} T_{2}$ and $G_{4} T_{3}$ repeat-specific oligonucleotides. Duplicate dot blots were prepared carrying serial dilutions in the amounts indicated of a Bluescript plasmid containing $21 \mathrm{G}_{4} \mathrm{~T}_{2}$ repeats $\left(\mathrm{pG}_{4} \mathrm{~T}_{2}-21\right)$, a Bluescript plasmid containing $18 \mathrm{G}_{4} \mathrm{~T}_{3}$ repeats $\left(\mathrm{pG}_{4} \mathrm{~T}_{3}-18\right)$, and the Bluescript plasmid alone. The blots were first probed with a radiolabeled oligonucleotide of the T7 promoter (T7pr) sequence as a control for the molar quantity of plasmid on the blots. The spots containing the 20-ng dilutions were quantitated by PhosphorImager in Table 1, and an autoradiograph is shown (T7pr). The probe was then washed off the blots, and the same blots were reprobed with radiolabeled oligonucleotides having the sequence $5^{\prime} G_{2} T_{2}\left(G_{4} T_{2}\right)_{3} G$ as the $G_{4} T_{2}$-specific probe and $5^{\prime} \mathrm{T}_{3}\left(\mathrm{G}_{4} \mathrm{~T}_{3}\right)_{3}$ as the $\mathrm{G}_{4} \mathrm{~T}_{3}$-specific probe. The spots containing the 20-ng dilutions were quantitated by PhosphorImager in Table 1 , and autoradiographs of the entire blots are shown.

nucleotides, the levels of cross-hybridization to the Bluescript vector and to the nonspecific repeat sequence were negligible under these conditions $(\leqslant 1 \%)$. The relative hybridization signal for each telomeric probe was normalized to the molar amount of plasmid DNA on the blot, based on the T7 promoter control. The radioactivity from the 20-ng spots of this (Fig. 5) and a duplicate set of blots (autoradiograph not shown) was quantitated using a PhosphorImager (Table 1). Table 1 shows that the relative $\mathrm{G}_{4} \mathrm{~T}_{2} / \mathrm{T} 7$ oligonucleotide hybridization was 1.63 for $\mathrm{pG}_{4} \mathrm{~T}_{2}-21$, and the relative $\mathrm{G}_{4} \mathrm{~T}_{3} / \mathrm{T} 7$ oligonucleotide hybridization was 0.63 for $\mathrm{pG}_{4} \mathrm{~T}_{3}-18$. Thus, hybridization of the $G_{4} T_{2}$ probe to its specific telomeric repeat sequence resulted in a signal intensity 2.6 times greater than that obtained from hybridization of the $G_{4} T_{3}$ probe to its corresponding repeat sequence. This value was used in subsequent quantitations to determine the $G_{4} T_{3}$ repeat content and distribution of native micronuclear telomeres.

Purified micronuclear DNA was subjected to a gradual time course digestion with Bal31 (using duplicate zero time points|, and samples were cleaved with $M s e I$, and divided in half for duplicate Southern blots. The blots were probed with either the $G_{4} T_{2}$ or $G_{4} T_{3}$ oligonucleotide and washed under conditions to maximize specificity (Fig. 6). The test plasmid dot blots quantitated in Table 1 were included in the same bag with the corre-

Table 1. Quantitation of hybridization to plasmid dot blot

\begin{tabular}{|c|c|c|c|c|c|}
\hline \multicolumn{3}{|c|}{$\mathrm{pG}_{4} \mathrm{~T}_{2}-21$} & \multicolumn{3}{|c|}{$\mathrm{pG}_{4} \mathrm{~T}_{3}-18$} \\
\hline \multicolumn{2}{|c|}{ probe } & \multirow[b]{2}{*}{$\mathrm{G}_{4} \mathrm{~T}_{2} / \mathrm{T} 7 \mathrm{pr}$} & \multicolumn{2}{|c|}{ probe } & \multirow[b]{2}{*}{$\mathrm{G}_{4} \mathrm{~T}_{3} / \mathrm{T} 7 \mathrm{pr}$} \\
\hline $\mathrm{G}_{4} \mathrm{~T}_{2}^{\mathrm{a}}$ & $\mathrm{T} 7 \mathrm{pr}^{\mathrm{a}}$ & & $\mathrm{G}_{4} \mathrm{~T}_{3}{ }^{\mathrm{a}}$ & $\mathrm{T} 7 \mathrm{pr}^{\mathrm{a}}$ & \\
\hline 7.84 & 4.51 & 1.74 & 3.99 & 6.69 & 0.60 \\
\hline 7.51 & 4.84 & 1.55 & 4.22 & 7.33 & 0.58 \\
\hline 8.17 & 5.00 & 1.63 & 5.01 & 7.17 & 0.70 \\
\hline 8.12 & 5.04 & 1.61 & 4.60 & 7.00 & 0.66 \\
\hline Mean & & 1.63 & & & 0.63 \\
\hline S.D. ${ }^{b}$ & & 0.08 & & & 0.06 \\
\hline
\end{tabular}

aPhosphorImager (Molecular Dynamics, CA) units, $\times 10^{5}$

${ }^{\mathrm{b}} \mathrm{Standard}$ deviation.

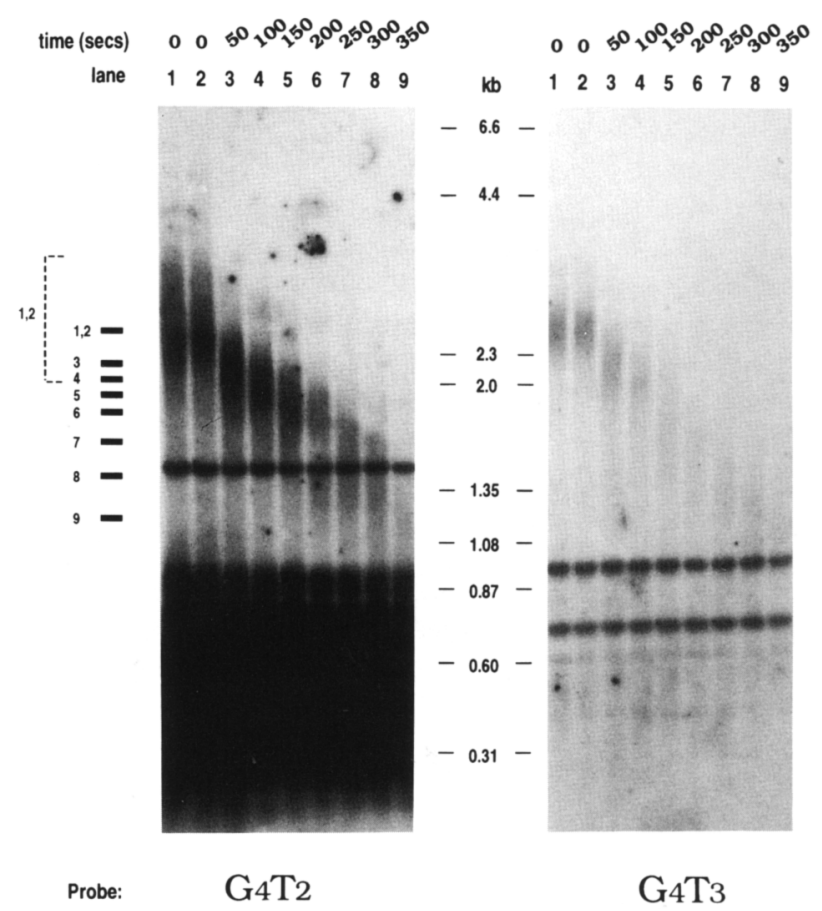

Figure 6. Southern blot analysis of Bal31-digested micronuclear DNA to determine the $\mathrm{G}_{4} \mathrm{~T}_{3}$ repeat content and distribution in native micronuclear telomeres. Purified micronuclear DNA was digested with Bal31 exonuclease, and aliquots were removed and enzymatic activity stopped at the indicated times. For reproducibility, two aliquots were removed before the addition of enzyme (zero time point). DNA samples were then digested with the restriction enzyme MseI, and each sample was divided in half and separated by electrophoresis in the same agarose gel so that duplicate blots could be prepared. Southern blots were probed with radiolabeled oligonucleotides having the sequence $5^{\prime} \mathrm{GT}_{2}\left(\mathrm{G}_{4} \mathrm{~T}_{2}\right)_{3} \mathrm{G}$ as the $\mathrm{G}_{4} \mathrm{~T}_{2}$-specific probe and $5^{\prime} T_{3}\left(G_{4} T_{3}\right)_{3}$ as the $G_{4} T_{3}$-specific probe. The broken line to the left of the $\mathrm{G}_{4} \mathrm{~T}_{2}$ autoradiograph indicates the 2.0 - to $3.4 \mathrm{~kb}$ region of the zero time point samples (lanes 1,2 ) quantitated by a PhosphorImager in Table 2. The solid bars (left) indicate the position of the Bal31-digested samples quantitated by a PhosphorImager in Table 2, and the numbers indicate which lane was quantitated in this region. The signals from identical positions of both blots were quantitated. 
sponding micronuclear DNA blot during hybridization and washes. Thus, there could be no potential variation in signal intensity because of differences in ionic strength or temperature. The specificity of the probes is further seen on the blots in Figure 6 by the lack of hybridization of the $\mathrm{G}_{4} \mathrm{~T}_{3}$ oligonucleotide to most chromosome-internal $\mathrm{G}_{4} \mathrm{~T}_{2}$ repeat tracts. Only two Bal31-resistant fragments were strongly detected by the $G_{4} T_{3}$ probe. The origin of these chromosome-internal $G_{4} T_{3}$ tracts is unknown, and like their $\mathrm{G}_{4} \mathrm{~T}_{2}$ counterparts, they were not detectable in macronuclear DNA /data not shown).

The results from this experiment were used first to determine the overall $\mathrm{G}_{4} \mathrm{~T}_{3}$ repeat composition in fulllength native micronuclear telomeres. Before Bal31 digestion, the bulk of the telomeric DNA fragments was 2.0-3.4 kb in length (Fig. 6, lanes 1,2; region marked by broken line). This region of both blots in the two zero time point lanes was quantitated by PhosphorImager analysis (Table 2). After correcting for the 2.6-fold difference in relative signal between the two oligonucleotides (from Table 1), it was determined that $28 \%$ of the total telomeric DNA consists of $\mathrm{G}_{4} \mathrm{~T}_{3}$ repeats, corresponding to $0.6-1.0 \mathrm{~kb}$ per telomere. Equivalent values (ranging from 24 to $36 \%$ ) were consistently obtained from different experiments using the same DNA and also a different micronuclear DNA preparation from another stock of the same strain. Similar results were also obtained from five other $T$. thermophila laboratory strains, including the most divergent C3 strain (data not shown).

As described above, all 19 telomere clones contained one or more centromere-proximal $\mathrm{G}_{4} \mathrm{~T}_{3}$ repeats adjacent to the distal $G_{4} T_{2}$ tracts. Because the largest cloned $G_{4} T_{3}$ tract $(\sim 0.3 \mathrm{~kb})$ was less than half the size determined to be present in the average native telomere, we addressed the possibility that the remaining 0.3 - to $0.7-\mathrm{kb} \mathrm{G}_{4} \mathrm{~T}_{3}$ tracts present in the native micronuclear DNA are lo-

Table 2. Quantitation of $G_{4} T_{2}$ and $G_{4} T_{3}$ hybridization to Bal31-digested micronuclear DNA

\begin{tabular}{lccccc}
\hline $\begin{array}{l}\text { Gel } \\
\text { lane }\end{array}$ & $\begin{array}{l}\text { Bal31 } \\
\text { digestion } \\
\text { time }(\mathrm{sec})\end{array}$ & $\begin{array}{l}\text { Quantitated } \\
\text { sample (kb) }\end{array}$ & $\mathrm{G}_{4} \mathrm{~T}_{3}{ }^{\mathrm{b}}$ & $\begin{array}{l}\mathrm{G}_{4} \mathrm{~T}_{3}, \\
\text { corrected }^{\mathrm{c}}\end{array}$ & $\mathrm{G}_{4} \mathrm{~T}_{2}{ }^{\mathrm{b}}$ \\
\hline 1 & 0 & $2.0-3.4$ & 74.2 & 193 & 489 \\
2 & 0 & $2.0-3.4$ & 69.3 & 180 & 450 \\
1 & 0 & 2.50 & 6.7 & 17.5 & 33.4 \\
2 & 0 & 2.50 & 5.6 & 14.6 & 36.3 \\
3 & 50 & 2.20 & 4.8 & 12.5 & 40.2 \\
4 & 100 & 2.05 & 3.8 & 9.9 & 31.5 \\
5 & 150 & 1.90 & 2.1 & 5.5 & 25.6 \\
6 & 200 & 1.75 & 1.5 & 3.9 & 13.2 \\
7 & 250 & 1.55 & 1.9 & 4.9 & 10.2 \\
8 & 300 & 1.35 & 2.4 & 6.2 & 8.8 \\
9 & 350 & 1.15 & 3.4 & 8.8 & 4.9 \\
\hline
\end{tabular}

${ }^{a}$ Fig. 6, lane from which sample was quantitated.

bPhosphorImager (Molecular Dynamics, CA) units, $\times 10^{3}$. 'PhosphorImager units $\times 2.6$ correction factor from Table 1, $\times 10^{3}$.

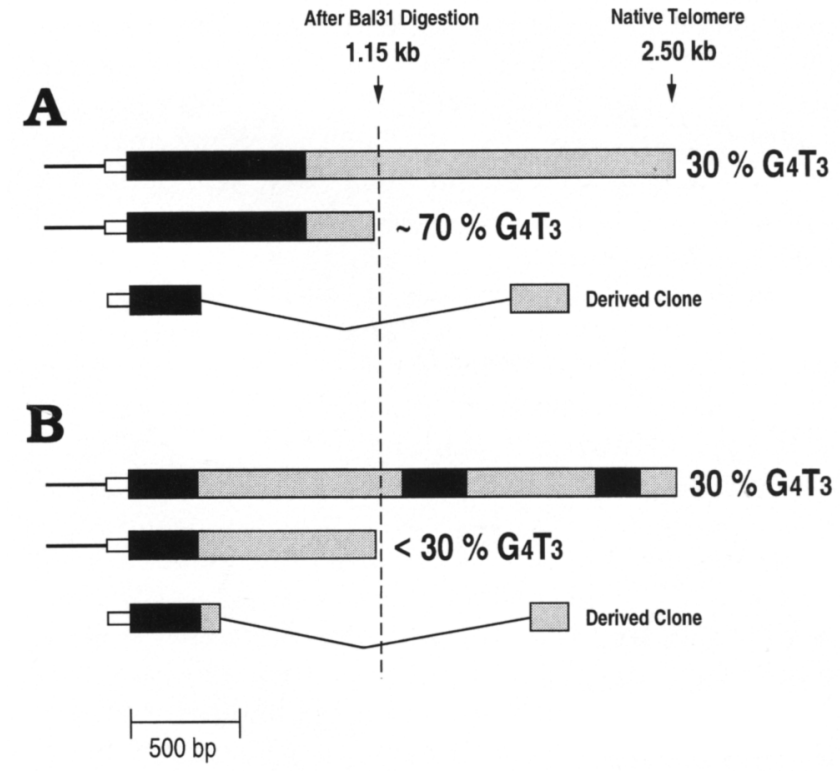

Figure 7. Schematic diagram illustrating two possible configurations of native micronuclear telomeres having $\sim 30 \% \mathrm{G}_{4} \mathrm{~T}_{3}$ repeat composition. Large solid bars indicate $\mathrm{G}_{4} \mathrm{~T}_{3}$ tracts, large shaded bars indicate $\mathrm{G}_{4} \mathrm{~T}_{2}$ tracts, and small open bars indicate complex TASs. $(A)$ A single $G_{4} T_{3}$ tract confined to the centromere-proximal region is depicted. $(B) \mathrm{A} \mathrm{G}_{4} \mathrm{~T}_{3}$ tract corresponding to the largest cloned $G_{4} T_{3}$ tract $(\sim 45$ repeats $)$ is depicted centromere proximally, and the remaining $G_{4} T_{3}$ repeats are arbitrarily spaced more distally. Below each configuration is shown the resulting telomeric fragment after digestion of 1.35 $\mathrm{kb}$ by $\mathrm{Ba} 31$, indicated by a vertical broken line, and the predicted percent $\mathrm{G}_{4} \mathrm{~T}_{3}$ composition. The $1.15 \mathrm{~kb}$ is the last position that was analyzed by Southern blot PhosphorImager quantitation, because of the strong hybridization signal from the internal telomere-like repeats masking the signal of the smaller telomeric fragments. A possible derivation of telomere clone from each configuration of native telomere is also depicted; the lines represent regions that would have been deleted during the cloning process.

cated more distally. In addition, as the most distal $500 \mathrm{bp}$ of telomeric DNA had been digested before cloning, it was possible that large $G_{4} T_{3}$ tracts could have been present near the chromosome termini. Schematic diagrams of two possible native telomere configurations are presented in Figure 7, which depicts an average 2.5-kb telomeric fragment that contains 100 -bp complex TAS and $\sim 700-$ bp $_{4} \mathrm{~T}_{3}$ repeats. In figure $7 \mathrm{~A}$, all $\mathrm{G}_{4} \mathrm{~T}_{3}$ repeats are positioned centromere proximally. In this case, digestion of $1.35 \mathrm{~kb}$ by Bal31 (as in Fig. 6, lane 9) would result in a final fragment having $\sim 70 \% \mathrm{G}_{4} \mathrm{~T}_{3}$ composition. Alternatively, if the native telomeres contain large tracts of $G_{4} T_{3}$ repeats more distally, shown arbitrarily positioned in Figure 7B, the same extent of Bal31 digestion would result in a fragment having considerably less $\mathrm{G}_{4} \mathrm{~T}_{3}$ repeat composition, in this example, $<30 \%$.

By quantitating the relative repeat signal during the course of Bal31 digestion in Figure 6, we investigated the position of the $G_{4} T_{3}$ tracts in native telomeres. Samples 
from each lane of the two blots in Figure 6 were quantitated by PhosphorImager analysis. To avoid artifactual signals and those from internal telomere-like repeats, samples of a narrow size range were chosen, which corresponded approximately to the average telomeric fragment, decreasing in size roughly linearly during Bal31 digestion (indicated by bars to the left of the $\mathrm{G}_{4} \mathrm{~T}_{2}$ blot in Figure 6). The data presented in Table 2 indicate that although the hybridization signal obtained with each probe decreased during digestion las expected because of the increased separation of the smaller sized fragments in the gel), a much greater proportion of the $\mathrm{G}_{4} \mathrm{~T}_{3}$ signal remained at the later time points; $55 \%$ of the original $\mathrm{G}_{4} \mathrm{~T}_{3}$ signal was still present at the last time point, whereas only $14 \%$ of the $\mathrm{G}_{4} \mathrm{~T}_{2}$ signal remained. In addition, the $\mathrm{G}_{4} \mathrm{~T}_{3}$ repeat composition at the last Bal31 time point (Fig. 6, lane 9) was calculated as a percentage of the combined $\mathrm{G}_{4} \mathrm{~T}_{2}+\mathrm{G}_{4} \mathrm{~T}_{3}$ signals. At the final time point, when $1.35 \mathrm{~kb}$ has been lost from the telomeres, the remaining 1.15-kb fragments have a $\mathrm{G}_{4} \mathrm{~T}_{3}$ composition of $64 \%$. These results are consistent with an internal localization of the $G_{4} T_{3}$ repeats, as depicted in Figure 7A. This determination has limitations, however, because of inherent telomere length variability, possible nonuniform rates of Bal31 activity, and due to the inability to analyze telomeric fragments shorter than $\sim 1.0 \mathrm{~kb}$ in Figure 6 , because of masking by the internal telomere-like repeats. Therefore, we cannot completely rule out the existence of some distally located $\mathrm{G}_{4} \mathrm{~T}_{3}$ repeats. Within these limitations, we conclude that the $\mathrm{G}_{4} \mathrm{~T}_{3}$ tracts are positioned centromere proximally to most or all of the $\mathrm{G}_{4} \mathrm{~T}_{2}$ repeats in native micronuclear telomeres.

\section{Discussion}

Here, we report the identification and cloning of micronuclear telomeres from $T$. thermophila, the first ciliate micronuclear telomeres to be isolated. Previous results from T. thermophila (Shampay and Blackburn 1989) and the hypotrichous ciliate Oxytricha fallax (Dawson and Herrick 1984) have indicated the probability that ciliate micronuclear telomeres contain the same repeat sequence as their macronuclear counterparts. We report that the distal telomeric repeat sequence in the T. thermophila micronucleus is the same as that found in the macronucleus, but the micronuclear telomere sequence is nonetheless unique in several respects. Thus, the three $T$. thermophila organelle genomes have telomeres that are distinct in sequence and in sequence arrangement: the long telomeres containing inner $\mathrm{G}_{4} \mathrm{~T}_{3}$ repeat tracts of the micronucleus; the short $G_{4} T_{2}$ telomeres of the macronucleus; and the mitochondrial telomeres having unusually complex repeat sequences (Morin and Cech 1988).

One fundamental difference between the telomeric DNA from the two $T$. thermophila nuclei is length. The bulk of micronuclear telomeric DNA (including both types of repeats) ranges in size from 2.0 to $3.4 \mathrm{~kb}$, whereas macronuclear telomeres are only $0.3-0.5 \mathrm{~kb}$. It is worth noting that the macronuclear telomere length is quite typical for a unicellular organism [e.g., yeasts (Shampay et al. 1984; McEachern and Blackburn 1994) or Chlamydomonas (Petracek et al. 1990)], whereas the micronuclear telomere length more closely reflects that of typical higher eukaryotes [e.g., Arabidopsis (Richards et al. 1992) or Ascaris (Muller et al. 1991)]. It is possible that the length difference in the two T. thermophila nuclei is the result of different selective pressures. In the macronucleus, shorter telomeres may be advantageous, supported by the observation that cells with shorter macronuclear telomeres have a growth advantage over cells with longer telomeres (Larson et al. 1987). In the micronucleus, perhaps the larger stretches of telomeric DNA are required for some unknown specific mitotic or meiotic telomere function. Interestingly, in humans, telomere length has also been shown to be significantly greater in the germ line than in somatic cells (for review, see de Lange 1994), and it has been proposed that this length difference is the result of a telomerase activity, which is greater in germ cells. The telomere length disparity seen in the two $T$. thermophila nuclei may reflect differences in the regulation of telomerase activity or other telomeric proteins. It is known that macronuclear telomeres are synthesized by telomerase during vegetative growth and de novo during development in mating cells (Yu et al. 1990; Yu and Blackburn 1991), and some evidence indicates that telomerase activity is increased during mating (Greider and Blackburn 1985; Avilion et al. 1992). Whether micronuclear telomere synthesis follows the temporal pattern of macronuclear telomere synthesis or whether the micronucleus has its own timing for telomere synthesis, independent of macronuclear events, is unknown. The latter possibility is suggested by the fact that DNA replication in the two nuclei occurs at different times during the cell cycle, as does nuclear division (McDonald 1973). We cannot exclude the possibility that telomerase acts on the micronuclear telomeres only during mating, and that the longer telomeres in this nucleus are necessary to compensate for inactive telomerase during vegetative growth. Studies of the mechanism and timing of telomere synthesis in the micronucleus will now be facilitated by the identification of the micronuclear telomere sequence.

Another difference between the telomeres of the two $T$. thermophila nuclei concerns TASs. All macronuclear TASs identified have an extremely low G/C content, $\sim 5 \%$, and appear to have no sequence relationship to one another (Yokoyama and Yao 1986; Spangler et al. 1988; $\mathrm{Yu}$ and Blackburn 1991). In contrast, the $50 \mathrm{bp}$ immediately adjacent to the telomeric repeats in all six cloned micronuclear TASs has a high G/C content of $\sim 50 \%$, high relative even to the $\sim 25 \%$ overall $\mathrm{G} / \mathrm{C}$ content of the micronuclear genome (Prescott 1994). In addition, all micronuclear TASs identified have a high degree of homology to each other, ranging from 55 to $87 \%$ identity.

The one TAS that was tested, TAS A, hybridized only to micronuclear telomeres and was not present in the macronucleus. These results indicate that TAS A is among those sequences eliminated during macronuclear 
differentiation. Approximately $10-20 \%$ of the micronuclear genome is eliminated during macronuclear development in conjugating $T$. thermophila (for review, see Karrer 1986). This process involves the temporally regulated, precise excision of specific sequences and families of sequences, followed by their active degradation. Because TAS A is not found in macronuclear DNA, and the adjacent $G_{4} T_{3}$ repeats also have not been found in any macronuclear telomere clone or by hybridization to macronuclear DNA, it is plausible that all micronuclear telomeric DNA is lost during differentiation. It is possible that some aspect of the micronuclear telomere structure is detrimental to the macronucleus and, therefore, is specifically eliminated. Alternatively, perhaps there is a mechanistic link between the elimination of the micronuclear telomeres and the chromosome-internal $G_{4} T_{2}$ tracts, although the reason for the loss of these or any other sequences is not known.

The most novel feature of the T. thermophila micronuclear telomeres is the presence of long homogeneous tracts of a variant repeat. Analysis of the $G_{4} T_{3}$ content and distribution in native micronuclear telomeres indicates the presence of $0.6-$ to $1.0-\mathrm{kb} \mathrm{G}_{4} \mathrm{~T}_{3}$ sequence per telomere, most likely localized centromere proximally. We cannot exclude the possibility that the native micronuclear telomeres have some interspersion of the two types of repeat or contain yet another variant repeat sequence, which is undetectable in our hybridization assay designed specifically for $G_{4} T_{3}$ and $G_{4} T_{2}$ repeats. However, the complete lack of any configuration other than homogeneous $\mathrm{G}_{4} \mathrm{~T}_{3}$ tracts followed by homogeneous $\mathrm{G}_{4} \mathrm{~T}_{2}$ tracts in every cloned micronuclear telomere argues against significant interspersed regions or additional variant repeats.

Analysis of micronuclear DNA from five other T. thermophila strains indicated a similar $\mathrm{G}_{4} \mathrm{~T}_{3}$ repeat composition $(24-36 \%)$, although the variant $\mathrm{G}_{4} \mathrm{~T}_{3}$ repeat was not detected in micronuclear telomeres from a closely related species, Tetrahymena malaccensis (K.E. Kirk and E.H. Blackburn, unpubl.). It should be noted that $T$. thermophila macronuclear telomeres are extremely homogeneous, consisting virtually exclusively of $\mathrm{G}_{4} \mathrm{~T}_{2}$ repeats. Of $>400$ macronuclear telomeric repeats sequenced, only one $G_{5} T_{2}$ variant was found (Budarf and Blackburn 1986; Spangler et al. 1988). Given the homogeneity of the micronuclear $G_{4} T_{3}$ tracts, their conservation in all $T$. thermophila strains examined, and their absence in macronuclear telomeres, it is tempting to speculate that the $G_{4} T_{3}$ tracts might play a role in some specialized telomere function of the micronucleus, such as mitotic chromosome segregation or meiosis, or in telomere length regulation. Perhaps there are specific $\mathrm{G}_{4} \mathrm{~T}_{3}$-binding proteins in the micronucleus. It is interesting to note that although $\mathrm{G}_{4} \mathrm{~T}_{3}$ repeats are not normally found in wild-type macronuclear telomeres, they can be tolerated in vivo when synthesized onto the ends of macronuclear chromosomes by a template mutation of the telomerase RNA gene. Of several variant telomeric repeat sequences that have been synthesized in this manner in vivo, the $G_{4} T_{3}$ variant is the only se- quence that is not lethal (Yu et al. 1990; D. Gilley and E.H. Blackburn, pers. comm.).

A telomere configuration in which there are distinct, homogeneous arrays of two different telomeric repeats, such as that found in the $T$. thermophila micronucleus, has not been identified previously. Most eukaryotic telomeres contain uniform arrays of a single telomeric repeat. Exceptions include $S$. cerevisiae telomeres that are entirely made up of irregular repeats, and the telomeres of Paramecium tetraurelia (Forney and Blackburn 1988) and certain Candida tropicalis strains (McEachern and Blackburn 1994), which are composed of two distinct variants seemingly randomly dispersed. In some eukaryotes, the distal telomeric DNA is uniformly composed of a single telomeric repeat, but the proximal regions contain dispersed variants. For example, in Arabidopsis thaliana, the outermost repeats are present in a homogeneous tract and, moving inward, a stretch of heterogeneous variant repeats is found, followed by a stretch of highly degenerate repeats, until the complex TAS is reached (Richards et al. 1992). In humans, the distal telomeric repeats are homogeneous, but several variant repeats are scattered among the more inner repeats (Brown et al. 1990). It is not known whether the variant or degenerate telomeric repeats found in the inner domains of some organisms have a function or whether they are merely tolerated mutations.

Telomeric DNA can be envisioned as having two domains with a somewhat indeterminate border: one outer domain in which the "faithful" telomeric repeats are the result of relatively recent telomerase-mediated synthesis, and an inner, possibly degenerate, region that is replicated solely by conventional DNA polymerases. It seems probable that the $\mathrm{G}_{4} \mathrm{~T}_{3}$ tracts in the $T$. thermophila micronuclear telomeres are part of an inner domain that is not a product of telomerase activity during vegetative growth. What is the origin of the $G_{4} T_{3}$ variant repeats in the micronuclear telomeres? One possibility is that they are the evolutionary remnant of an ancient telomerase enzyme that synthesized $\mathrm{G}_{4} \mathrm{~T}_{3}$ repeats. In this model, however, it is surprising that no mutations have appeared in the $G_{4} T_{3}$ repeat tracts, unless there is a very strong selection against any such mutations. Another possibility is that they arose directly from the amplification and homogenization of a telomeric repeat mutation that occurred originally in the inner domain of a micronuclear telomere. Several mechanisms have been invoked for the creation and maintenance of homogeneous repetitive DNA sequences (Smith 1976; Dover 1982; Lohe and Brutlag 1987), and one or more of these may have been used throughout the evolution of the micronuclear telomeres. An alternative hypothesis is that the micronucleus has two different, sequential telomerase activities that function to synthesize its telomeres: one bearing a $\mathrm{G}_{4} \mathrm{~T}_{3}$-templating RNA expressed uniquely in the micronucleus, and the second carrying the macronuclear-expressed $\mathrm{G}_{4} \mathrm{~T}_{2}$ version. Therefore, the micronucleus would necessarily possess two telomerase RNA genes. We have searched for a second gene by Southern blot hybridization to the macronucleus-expressed ver- 
sion and have not found any indication of a second copy in the micronucleus (K.E. Kirk and E.H. Blackburn, unpubl.).

The results presented here provide the foundation for future investigations into the regulation of germ-line micronuclear telomere length and synthesis. In addition, it should be possible to alter the outermost telomeric repeat sequences of micronuclear chromosomes and study the effect of such mutations on micronuclear mitotic divisions and on meiosis.

\section{Materials and methods}

Strains and growth conditions

Routine growth conditions for $T$. thermophila have been described previously (Orias and Bruns 1975). Strains $P B-9 R$ [ChxA2/ChxA2 (cy-s)] mating type II and VII were cultured in $2 \%$ PPYS, cells were starved and mated as described previously (Wyman and Blackburn 1991), and progeny were selected by growth in $15 \mu \mathrm{g} / \mathrm{ml}$ of cycloheximide. For large-scale growth, cells were inoculated into 40 liters of prewarmed $2 \%$ PPYS containing $100 \mathrm{U} / \mathrm{ml}$ of penicillin $\mathrm{G}, 100 \mu \mathrm{g} / \mathrm{ml}$ of streptomycin,

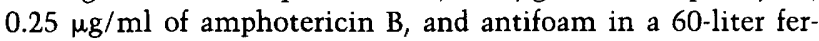
mentor to an initial concentration of $10^{3} / \mathrm{ml}$. Cells were grown at $30^{\circ} \mathrm{C}$ with $25 \mathrm{lb}$ air pressure and $125 \mathrm{rpm}$ stirring to a final cell density of $1.4 \times 10^{5} / \mathrm{ml}$. E. coli strain XLI-blue MRF' (Stratagene) was used for propagation of a phage library, E. coli strain SOLR (Stratagene) was used for the excision of Bluescript plasmids from the phage vector, strain DH5 $\alpha$ was used for amplification of $\mathrm{pG}_{4} \mathrm{~T}_{2}-21$, and strain XL1-blue (Stratagene) was used for amplification of $\mathrm{pG}_{4} \mathrm{~T}_{3}-18$.

\section{Purification of nuclei}

Micronuclei were purified by a modification of procedures described previously (Gorovsky et al. 1975; Allen et al. 1983). A 40 -liter culture of $1.4 \times 10^{5}$ cells $/ \mathrm{ml}$ was prepared $\sim 75$ generations postmating. Cells were concentrated across a Millipore membrane, centrifuged at $3000 \mathrm{rpm}$ for $5 \mathrm{~min}$ using a Sorvall GS-3 rotor, and washed in $0.2 \mathrm{M}$ sucrose, $10 \mathrm{~mm}$ Tris- $\mathrm{HCl}(\mathrm{pH}$ 7.5 ), and $2 \mathrm{mM} \mathrm{MgCl}_{2}$. Remaining procedures were carried out at $4^{\circ} \mathrm{C}$. Cells were resuspended in 1.8 liters of medium A (Allen et al. 1983), and $18 \mathrm{ml}$ of $n$-octanol was added slowly with stirring. Cells were lysed in a 1-liter Waring Blendor in two batches, and nuclei were released from the cell debris by five cycles of blending for $30 \mathrm{sec}$ at 5 -min intervals. The lysate was then centrifuged in a Sorvall GSA rotor at $3000 \mathrm{rpm}$ for $7 \mathrm{~min}$, and the supernatant (enriched for micronuclei) was blended as before. This material was centrifuged at $6000 \mathrm{rpm}$ for $15 \mathrm{~min}$, and the pellets containing micronuclei and contaminating macronuclei were resuspended in $48 \mathrm{ml}$ of medium A. Separation of micronuclei and macronuclei was achieved on Percoll (Sigma) gradients, essentially as described previously (Allen et al. 1983). The nuclei were layered onto $8 \times 24 \mathrm{ml}$ of preformed $25 \%$ Percoll gradients and centrifuged at $3000 \mathrm{rpm}$ for $18 \mathrm{~min}$ in an HB-4 rotor. All except the bottom $5 \mathrm{ml}$ of the gradient was discarded, and the nuclei were washed once in medium A containing $0.2 \%$ NP-40 and centrifuged as above. The pellet was resuspended in $20 \mathrm{ml}$ of medium A, layered onto $4 \times 24 \mathrm{ml}$ of preformed $50 \%$ Percoll gradients, and centrifuged at $3000 \mathrm{rpm}$ for $8.5 \mathrm{~min}$. The micronuclear fractions were drawn from the top one-third of the tubes, and the macronuclei were collected from the bottom of the tubes. The micronuclei were washed and separated again on a second $50 \%$ Percoll gradient. The final fractions were washed twice in medium A and resuspended in $10 \mathrm{ml}$ of $60 \mathrm{mM} \mathrm{KCl}, 15$
$\mathrm{mM} \mathrm{NaCl}, 0.5 \mathrm{~mm}$ spermidine, $0.15 \mathrm{~mm}$ spermine, and $15 \mathrm{~mm}$ Tris- $\mathrm{HCl}(\mathrm{pH} 7.4)$. A $10 \%$ yield of micronuclei was obtained (based on 1 micronucleus/cell-starting material), generating a 300 - to 400 -fold purification from macronuclei.

\section{Isolation of DNA}

Nuclei were lysed by adding $18 \mathrm{ml}$ of $1.5 \%$ sarcosyl, $0.5 \mathrm{M}$ EDTA, and $10 \mathrm{~mm}$ Tris- $\mathrm{HCl}(\mathrm{pH} 7.4)$ and incubating for $30 \mathrm{~min}$ at $50^{\circ} \mathrm{C}$. Ten milliliters of $0.5 \mathrm{~m}$ EDTA, $10 \mathrm{~mm}$ Tris- $\mathrm{HCl} / \mathrm{pH}$ 7.4), containing $0.2 \mathrm{mg} / \mathrm{ml}$ of pronase, was then added and incubated overnight. The macronuclear DNA sample was extracted with phenol-chloroform and ethanol precipitated. The micronuclear DNA sample was separated from contaminating macronuclear rDNA by Hoechst- $\mathrm{CsCl}$ gradient. For every 24 $\mathrm{ml}$ of DNA solution, $0.5 \mathrm{mg}$ of Hoechst 33342 and $48 \mathrm{ml}$ of saturated $\mathrm{CsCl}$ were added and centrifuged on a VTi 50 rotor at $42,000 \mathrm{rpm}$ for $24 \mathrm{hr}$ at $18^{\circ} \mathrm{C}$. The micronuclear DNA band was collected, and the Hoechst dye was removed by extraction with isopropanol; DNA was ethanol precipitated. Yield was $\sim 1 \mathrm{pg}$ of DNA/micronucleus.

\section{Bal31 nuclease digestion}

Typical Bal31 nuclease digestions contained $7 \mu \mathrm{g}$ of DNA placed into $35 \mu \mathrm{l}$ of buffer containing $12 \mathrm{mM} \mathrm{CaCl}_{2}, 12 \mathrm{mM}$ $\mathrm{MgCl}_{2}, 0.2 \mathrm{M} \mathrm{NaCl}, 20 \mathrm{~mm}$ Tris- $\mathrm{HCl}$ ( $\mathrm{pH} \mathrm{8.0)}$, and $1 \mathrm{mM}$ EDTA, preequilibrated at $30^{\circ} \mathrm{C}$. Five microliters was removed and added to 0.1 volume of $0.2 \mathrm{M}$ EGTA (zero time point). To the remaining DNA, 0.4 units of Bal31 nuclease (New England $\mathrm{Bi}$ olabs) was added and vortexed, and the mixture was incubated at $30^{\circ} \mathrm{C}$. Aliquots $(5 \mu \mathrm{l})$ were removed at various times and added to EGTA to stop the reaction. The samples were then diluted up to $40 \mu \mathrm{l}$ in the appropriate buffer and restriction enzyme.

\section{Cloning micronuclear telomeric DNA}

Standard techniques (Sambrook et al. 1989) and manufacturers' suggestions were used. Forty micrograms of micronuclear DNA was digested with 2 units of $\mathrm{Bal} 31$ for $1 \mathrm{~min}$ at $30^{\circ} \mathrm{C}$, and the extent of telomere shortening was verified to be $\sim 500$ bp by Southern blot analysis. The DNA ends were then made flush by T4 DNA polymerase and ligated to $8 \mu \mathrm{g}$ of NotI linkers. DNA was digested with NotI and Tsp509I (New England Biolabs). The fragments were separated by $0.8 \%$ agarose electrophoresis and the region of the gel corresponding to $1.0-3.5 \mathrm{~kb}$ was cut out, 2.5 $\mu \mathrm{g}$ of $E$. coli DNA was added as carrier, and the DNA was purified using Geneclean (Bio 101, Inc.). The $\lambda$ Zap II vector (Stratagene) was prepared as follows: $1 \mu \mathrm{g}$ of undigested $\lambda$ DNA was digested with NotI, treated with calf intestinal phosphatase, and digested with EcoRI. The purified micronuclear telomeric DNA was ligated to the $\lambda$ Zap II vector for 2 days at $14^{\circ} \mathrm{C}$, and the DNA was packaged according to manufacturer's recommendations. The entire unamplified library $(2000$ plaques) was transferred to Hybond-N+ (Amersham) membrane and screened with a radiolabeled $\left(\mathrm{C}_{4} \mathrm{~A}_{2}\right)_{4}$ oligonucleotide according to manufacturer's suggestions. Twenty positive plaques were identified (one was later found to be nontelomeric). The Bluescript plasmids containing inserts were excised from the phage DNA following Stratagene's protocol.

\section{Sequencing telomeric clones}

Standard procedures were used to prepare plasmid DNA (Sambrook et al. 1989). Attempts to sequence through telomeric re- 
peats on both strands, using the $\mathrm{M} 13$ reverse sequencing primer $(-24)$ and the M13 sequencing primer $(-20)$ were only partially successful using a standard sequencing kit (U.S. Biochemical). Unambiguous results were obtained using a 7-deaza dGTP kit (U.S. Biochemical) to read the C-rich strand, primed by the T7 promoter primer; therefore, most sequencing data were derived from copying the C-rich strand.

\section{Plasmid construction}

$\mathrm{pG}_{4} \mathrm{~T}_{2}-21$ was constructed by ligating a BamHI fragment containing $21 \mathrm{G}_{4} \mathrm{~T}_{2}$ repeats [originally cloned from a macronuclear telomere (Challoner and Blackburn 1986)] into the BamHI site of Bluescript II SK(-) (Stratagene). $\mathrm{pG}_{4} \mathrm{~T}_{3}-18$ was constructed as follows. A micronuclear telomere clone [TAS $C_{;}\left(G_{4} T_{3}\right)_{\sim 37}$, $\left.\left(\mathrm{G}_{4} \mathrm{~T}_{2}\right)_{\sim 12}\right]$ was digested with NotI. The linearized plasmid was then subjected to a Bal31 digestion time course to progressively digest away the $G_{4} T_{2}$ repeats and some of the $G_{4} T_{3}$ repeats. DNA samples from four time points were treated with T4 DNA polymerase and T4 DNA ligase, and used to transform E. coli. Twelve transformant plasmids were sequenced, and one containing a tract of only $18 \mathrm{G}_{4} \mathrm{~T}_{3}$ repeats was chosen for further use.

\section{Dot blot assay}

$\mathrm{pG}_{4} \mathrm{~T}_{2}-21$ and $\mathrm{pG}_{4} \mathrm{~T}_{3}-18$ DNAs were prepared using a plasmid kit (Qiagen) following the manufacturer's protocol. Solutions containing $2.0,0.40$, and $0.08 \mu \mathrm{g} / \mathrm{ml}$ of each plasmid in $\mathrm{H}_{2} \mathrm{O}$ were boiled and placed on ice, and an equal volume of ice-cold 10× SSC (Sambrook et al. 1989) was added. One hundred microliters of each dilution was loaded onto the dot blot apparatus containing Hybond-N + membrane (Amersham), and the DNA was bound to the membrane using a UV Stratalinker (Stratagene). The denatured plasmids were hybridized to a series of $\mathrm{G}_{4} \mathrm{~T}_{2}$ - or $\mathrm{G}_{4} \mathrm{~T}_{3}$-specific radiolabeled oligonucleotide probes having different lengths and repeat permutations (not shown), and the maximum specificity was obtained with oligonucleotides $5^{\prime}$-GTT(GGGGTT) ${ }_{3}$ G and $5^{\prime}$-TTT(GGGGTTT) $)_{3}$. Hybridization of these two oligonucleotides took place at $30^{\circ} \mathrm{C}$, and washes were done at increasing temperatures in increments of $5^{\circ} \mathrm{C}$. Greater than 10 -fold specificity did not occur until above $45^{\circ} \mathrm{C}$, and nearly all hybridization signal was lost at $60^{\circ} \mathrm{C}$ for both oligonucleotides (not shown).

\section{Hybridization probes}

Oligonucleotide probes were $5^{\prime}$ end-radiolabeled using T4 polynucleotide kinase following standard protocol (Sambrook et al. 1989). $5^{\prime}$ (CCCCAA $)_{4}$ was used as a probe for the Southern blot in Figure 1 and as a probe to screen the micronuclear telomere library. 5'-GTT(GGGGTT) ${ }_{3} G$ was used as the $G_{4} T_{2}$-specific probe, and 5'TTT(GGGGTTT) $)_{3}$ was used as the $\mathrm{G}_{4} \mathrm{~T}_{3}$-specific probe in Figures 5 and 6 , and the T7 promoter primer $5^{\prime}$ TAATACGACTCACTATAGGGAGA was used in Figure 5. The TAS A probe used in Figure 3 was prepared as follows. Oligonucleotides 5'-AATTATAAATAAAATAGGTATAG and 5'-ACAACTTTGAGGTTGTTCGG were used as primers for the micronuclear TAS A clone in a PCR using reagents from the GeneAmp kit (Perkin Elmer Cetus). The amplified product was gel purified using Geneclean (Bio 101, Inc.) and was radiolabeled using reagents from the Multiprime DNA Labeling System (Amersham). The telomerase RNA probe used in Figure 3 was a gel-purified 570-bp Xhol fragment from JB101 (Yu et al. 1990), which was multiprime labeled.

\section{Hybridization conditions}

All hybridizations were carried out in $0.5 \mathrm{M} \mathrm{Na}_{2} \mathrm{HPO}_{4}, 7 \%$ SDS, and $1 \%$ BSA (Church and Gilbert 1984) overnight. The blots in Figure 1 were hybridized at $48^{\circ} \mathrm{C}$ and washed in $0.2 \mathrm{M} \mathrm{Na}_{2} \mathrm{HPO}_{4}$, $2 \%$ SDS, at $48^{\circ} \mathrm{C}$. The blots in Figure 3 were hybridized at $65^{\circ} \mathrm{C}$ and washed as above at $60^{\circ} \mathrm{C}$. The $\mathrm{G}_{4} \mathrm{~T}_{2}$ and $\mathrm{G}_{4} \mathrm{~T}_{3}$ blots in Figures 5 and 6 were hybridized at $30^{\circ} \mathrm{C}$ and washed in $0.05 \mathrm{M}$ $\mathrm{Na}_{2} \mathrm{HPO}_{4}, 2 \% \mathrm{SDS}$, at $55^{\circ} \mathrm{C}$. The blot using the $\mathrm{T} 7$ promoter probe in Figure 5 was hybridized at $25^{\circ} \mathrm{C}$ and washed in $0.2 \mathrm{M}$ $\mathrm{Na}_{2} \mathrm{HPO}_{4}, 2 \%$ SDS, at $25^{\circ} \mathrm{C}$.

\section{Acknowledgments}

We thank M.J. McEachern for helpful discussions throughout the course of this research and manuscript preparation, and A. Bhattacharyya, R.C. Gallagher, and H. Wang for their critical comments of the manuscript. This work was supported by National Institutes of Health grants GM26259 and GM32565 to E.H.B., and by an American Cancer Society Fellowship to K.E.K.

The publication costs of this article were defrayed in part by payment of page charges. This article must therefore be hereby marked "advertisement" in accordance with 18 USC section 1734 solely to indicate this fact.

\section{References}

Allen, S.L., T.C. White, J.P. Langmore, and M.A. Swancutt. 1983. Highly purified micro- and macronuclei from Tetrahymena thermophila isolated by Percoll gradients. J. Protozool. 30: $21-30$.

Allis, C.D., R.L. Allen, J.C. Wiggins, L.C. Chicoine, and R. Richman. 1984. Proteolytic processing of H1-like histones in chromatin: A physiologically and developmentally regulated event in Tetrahymena micronuclei. J. Cell Biol. 99: 16691677.

Avilion, A.A., L.A. Harrington, and C.W. Greider. 1992. Tetrahymena telomerase RNA levels increase during macronuclear development. Dev. Genet. 13: 80-86.

Bennett, C.B., A.L. Lewis, K.K. Baldwin, and M.A. Resnick. 1993. Lethality induced by a single site-specific doublestrand break in a dispensable yeast plasmid. Proc. Natl. Acad. Sci. 90: 5613-5617.

Blackburn, E.H. 1990. Telomeres: Structure and synthesis. J. Biol. Chem. 265: 5919-5921.

- 1992. Telomerases. Annu. Rev. Biochem 61: 113-129. 1994. Telomeres: No end in sight. Cell 77: 621-623.

Blackburn, E.H. and K.M. Karrer. 1986. Genomic reorganization in ciliated protozoa. Annu. Rev. Genet 20: 501-521.

Brown, W.R.A., P.J. MacKinnon, A. Villasante, N. Spurr, V.J. Buckle, and M.J. Dobson. 1990. Structure and polymorphism of human telomere-associated DNA. Cell 63: 119-132.

Budarf, M.L. and E.H. Blackburn. 1986. Chromatin structure of the telomeric region and $3^{\prime}$-nontranscribed spacer of Tetrahymena ribosomal RNA genes. J. Biol. Chem. 261: 363369.

Challoner, P.B. and E.H. Blackburn. 1986. Conservation of sequences adjacent to the telomeric $\mathrm{C}_{4} \mathrm{~A}_{2}$ repeats of ciliate macronuclear ribosomal DNA gene molecules. Nucleic Acids Res. 14: 6299-6311.

Cherry, J.M. and E.H. Blackburn. 1985. The internally located telomeric sequences in the germ-line chromosomes of Tetrahymena are at the ends of transposon-like elements. Cell 43: 747-758.

Chikashige, Y., D.-Q. Ding, H. Funabiki, T. Haraguchi, S. Mash- 
iko, M. Yanagida, and Y. Hiraoka. 1994. Telomere-led premeiotic chromosome movement in fission yeast. Science 264: 270-273.

Chung, H.-M.M., C. Shea, S. Fields, R.N. Taub, and L.H.T. Van der Ploeg. 1990. Architectural organization in the interphase nucleus of the protozoan Trypanosoma brucei: Location of telomeres and mini-chromosomes. EMBO /. 9: 2611-2619.

Church, G.M. and W. Gilbert. 1984. Genomic sequencing. Proc. Natl. Acad. Sci. 81: 1991-1995.

Cross, S.H., R.C. Allshire, S.J. McKay, N.I. McGill, and H.J. Cooke. 1989. Cloning of human telomeres by complementation in yeast. Nature 338: 771-776.

Dancis, B.M. and G.P. Holmquist. 1979. Telomere replication and fusion in eukaryotes. $J$. Theor. Biol. 78: 211-224.

Dawe, R.K., J.W. Sedat, D.A. Agard, and W.Z. Cande. 1994. Meiotic chromosome pairing in Maize is associated with a novel chromatin organization. Cell 76: 901-912.

Dawson, D. and G. Herrick. 1984. Telomeric properties of $\mathrm{C}_{4} \mathrm{~A}_{4^{-}}$ homologous sequences in micronuclear DNA of Oxytricha fallax. Cell 36: 171-177.

de Lange, T. 1994. Activation of telomerase in a human tumor. Proc. Natl. Acad. Sci. 91: 2882-2885.

Dover, G. 1982. Molecular drive: A cohesive mode of species evolution. Nature 299: 111-117.

Forney, J.D. and E.H. Blackburn. 1988. Developmentally controlled telomere addition in wild-type and mutant Paramecia. Mol. Cell. Biol. 8: 251-258.

Funabiki, H., I. Hagan, S. Uzawa, and M. Yanagida. 1993. Cell cycle-dependent specific positioning and clustering of centromeres and telomeres in fission yeast. $J$. Cell Biol. 121: 961-976.

Gorovsky, M.A., M.-C. Yao, J.B. Keevert, and G.L. Pleger. 1975. Isolation of micro-and macronuclei of Tetrahymena pyriformis. In Methods in cell biology (ed. D.M. Prescott), pp. 311-327. Academic Press, New York.

Gottschling, D.E., O.M. Aparicio, B.L. Billington, and V.A. Zakian. 1990. Position effect at $S$. cerevisiae telomeres: Reversible repression of pol II transcription. Cell 63: 751-762.

Greider, C.W. 1991. Telomeres. Curr. Opin. Cell Biol. 3: 444451.

Greider, C.W. and E.H. Blackburn. 1985. Identification of a specific telomere terminal transferase activity in Tetrahymena extracts. Cell 43: 405-413.

. 1989. A telomeric sequence in the RNA of Tetrahymena telomerase required for telomere repeat synthesis. Nature 337: 331-337.

Hochstrasser, M., D. Mathog, Y. Gruenbaum, H. Saumweber, and J.W. Sedat. 1986. Spatial organization of chromosomes in the salivary gland nuclei of Drosophila melanogaster. $J$. Cell Biol. 102: 112-123.

Kapler, G.M. 1993. Developmentally regulated processing and replication of the Tetrahymena rDNA minichromosome. Curr. Opin. Genet. Dev. 3: 730-735.

Karrer, K.M. 1986. The nuclear DNAs of holotrichous ciliates. In The molecular biology of ciliated protozoa (ed. J.G. Gall), pp. 85-111. Academic Press, New York.

Klein, F., L. Thierry, M.E. Cardenas, J.F.-X. Hofmann, D. Schweizer, and S.M. Gasser. 1992. Localization of RAPl and topoisomerase II in nuclei and meiotic chromosomes of yeast. J. Cell Biol. 117: 935-948.

Larson, D.D., E.A. Spangler, and E.H. Blackburn. 1987. Dynamics of telomere length variation in Tetrahymena. Cell 50: 477-483.

Lohe, A.R. and D.L. Brutlag. 1987. Adjacent satellite DNA segments in Drosophila structure of junctions. J. Mol. Biol. 194: 171-179.
Longtine, M.S., S. Enomoto, S.L. Finstad, and J. Berman. 1992. Yeast telomere repeat sequence (TRS) improve circular plasmid segregation, and TRS plasmid segregation involves the RAP1 gene product. Mol. Cell. Biol. 12: 1997-2009.

_. 1993. Telomere-mediated plasmid segregation in Saccharomyces cerevisiae involves gene products required for transcriptional repression at silencers and at telomeres. $G e$ netics 133: 171-182.

Martindale, D.W., C.D. Allis, and P.J. Bruns. 1985. RNA and protein synthesis during meiotic prophase in Tetrahymena thermophila. J. Protozool. 32: 644-649.

McClintock, B. 1939. The behavior of successive nuclear divisions of a chromosome broken at meiosis. Proc. Natl. Acad. Sci. 25: 405-416.

-1941. The stability of broken ends of chromosomes in Zea mays. Genetics 26: 234-282.

McDonald, B.B. 1973. Nucleic acids in Tetrahymena during vegetative growth and conjugation. In The biology of Tetrahymena (ed. A.M. Elliot), pp. 287-306. Dowden, Hutchinson, \& Ross, Stroudsburg, PA.

McEachern, M.J. and E.H. Blackburn. 1994. A conserved sequence motif within the exceptionally diverse telomeric sequences of budding yeasts. Proc. Natl. Acad. Sci. 91: 34533457.

McEachern, M.J. and J.B. Hicks. 1993. Unusually large telomeric repeats in the yeast Candida albicans. Mol. Cell Biol. 13: $551-560$.

G.B. and T.R. Cech. 1988. Mitochondrial telomeres: Surprising diversity of repeated telomeric DNA sequences among six species of Tetrahymena. Cell 52: 367-374.

Muller, F., C. Wickey, A. Spicher, and H. Tobler. 1991. New telomere formation after developmentally regulated chromosomal breakage during the process of chromatin diminution in Ascaris lumbicoides. Cell 67: 815-822.

Muller, H.J. and I.H. Herskowitz. 1954. Concerning the healing of chromosome ends produced by breakage in Drosophila melanogaster. Am. Nat. 88: 177-208.

Orias, E. and P.J. Bruns. 1975. Induction and isolation of $\mathrm{mu}-$ tants in Tetrahymena. In Methods in cell biology (ed. D.M. Prescott), pp. 247-282. Academic Press, New York.

Palladino, F., T. Laroche, E. Gilson, A. Axelrod, L. Pillus, and S.M. Gasser. 1993. SIR3 and SIR4 proteins are required for the positioning and integrity of yeast telomeres. Cell 75: 543-555.

Petracek, M.E., P.A. Lefebvre, C.D. Silflow, and J. Berman. 1990. Chlamydomonas telomere sequences are $\mathrm{A}+\mathrm{T}$-rich but contain three consecutive G-C base pairs. Proc. Natl. Acad. Sci. 87: 8222 -8226.

Prescott, D.M. 1994. The DNA of ciliated protozoa. Microbiol. Rev. 58: 233-267.

Richards, E.J., S. Chao, A. Vongs, and J. Yang. 1992. Characterization of Arabidopsis thaliana telomeres isolated in yeast. Nucleic Acids Res. 20: 4039-4046.

Romero, D. and E.H. Blackburn. 1991. A conserved secondary structure for telomerase RNA. Cell 67: 343-353.

Sambrook, J., E.F. Fritsch, and T. Maniatis. 1989. Molecular cloning: A laboratory manual. Cold Spring Harbor Laboratory Press, Cold Spring Harbor, New York.

Sandell, L.L. and V.A. Zakian. 1993. Loss of a yeast telomere: Arrest, recovery, and chromosome loss. Cell 75: 729-739.

Shampay, J. and E.H. Blackburn. 1989. Tetrahymena micronuclear sequences that function as telomeres in yeast. Nucleic Acids Res. 17: 3247-3260.

Shampay, J., J.W. Szostak, and E.H. Blackburn. 1984. DNA sequences of telomeres maintained in yeast. Nature 310: 154 157. 
Smith, G.P. 1976. Evolution of repeated DNA sequences by unequal crossover. Science 191: 528-535.

Spangler, E.A., T. Ryan, and E.H. Blackburn. 1988. Developmentally regulated telomere addition in Tetrahymena thermophia. Nucleic Acids Res. 16: 5569-5585.

Stargell, L.A. and M.A. Gorovsky. 1994. TATA-binding protein and nuclear differentiation in Tetrahymena thermophila. Mol. Cell. Biol. 14: 723-734.

Stargell, L.A., J. Bowen, C.A. Dadd, P.C. Dedon, M. Davis, R.G. Cook, C.D. Allis, and M.A. Gorovsky. 1993. Temporal and spatial association of histone $\mathrm{H} 2 \mathrm{~A}$ variant hvl with transcriptionally competent chromatin during nuclear development in Tetrahymena thermophila. Genes \& Dev. 7: 26412651.

Stavenhagen, J.B. and V.A. Zakian. 1994. Internal tracts of telomeric DNA act as silencers in Saccharomyces cerevisiae. Genes \& Dev. 8: 1411-1422.

Sugai, T. and K. Hiwatashi. 1974. Cytological and autoradiographic studies of the micronucleus at meiotic prophase in Tetrahymena pyriformis. J. Protozool. 21: 542-548.

Wyman, C. and E.H. Blackburn. 1991. Tel-1 transposon-like elements of Tetrahymena thermophila are associated with micronuclear genome rearrangements. Genetics 129: 57-67.

Yao, M.-C. and C.H. Yao. 1981. The repeated hexanucleotide C-C-C-C-A-A is present near free ends of macronuclear DNA of Tetrahymena. Proc. Natl. Acad. Sci. 78: 7436-7439.

Yokoyama, R. and M.-C. Yao. 1986. Sequence characterization of Tetrahymena macronuclear DNA ends. Nucleic Acids Res. 14: 2109-2122.

Yu, G.-L. and E.H. Blackburn. 1991. Developmentally programmed healing of chromosomes by telomerase in Tetrahymena. Cell 67: 823-832.

Yu, G.-L., J.D. Bradley, L.D. Attardi, and E.H. Blackburn. 1990. In vivo alteration of telomere sequences and senescence caused by mutated Tetrahymena telomerase RNAs. Nature 344: $12-6-132$ 


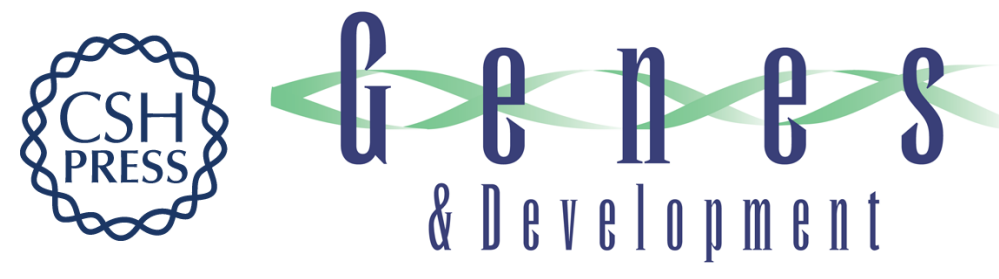

\section{An unusual sequence arrangement in the telomeres of the germ-line micronucleus in Tetrahymena thermophila.}

K E Kirk and E H Blackburn

Genes Dev. 1995, 9:

Access the most recent version at doi:10.1101/gad.9.1.59

References This article cites 60 articles, 25 of which can be accessed free at:

http://genesdev.cshlp.org/content/9/1/59.full.html\#ref-list-1

License

Email Alerting

Service

Receive free email alerts when new articles cite this article - sign up in the box at the top right corner of the article or click here.

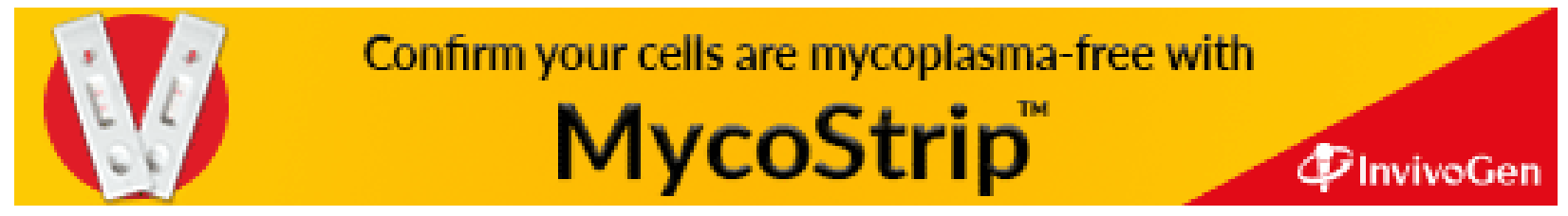

